University of Rhode Island

DigitalCommons@URI

Open Access Master's Theses

1995

\title{
THE ONTOLOGY OF FICTIONAL OBJECTS WITH SPECIAL REFERENCE TO ROMAN INGARDEN
}

Mark M. Brzozowski

University of Rhode Island

Follow this and additional works at: https://digitalcommons.uri.edu/theses

\section{Recommended Citation}

Brzozowski, Mark M., "THE ONTOLOGY OF FICTIONAL OBJECTS WITH SPECIAL REFERENCE TO ROMAN INGARDEN" (1995). Open Access Master's Theses. Paper 1535.

https://digitalcommons.uri.edu/theses/1535

This Thesis is brought to you for free and open access by DigitalCommons@URI. It has been accepted for inclusion in Open Access Master's Theses by an authorized administrator of DigitalCommons@URI. For more information, please contact digitalcommons-group@uri.edu. 


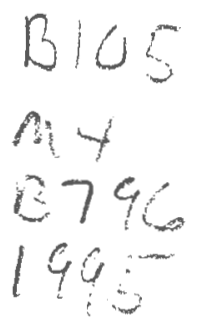

THE ONTOLOGY OF FICTIONAL OBJECTS WITH SPECIAL REFERENCE TO ROMAN INGARDEN

BY

MARK M. BRZOZOWSKI

A THESIS SUBMITTED IN PARTIAL FULFILLMENT OF THE

REQUIREMENTS FOR THE DEGREE OF

MASTER OF ARTS

IN

PHILOSOPHY

34667

UNIVERSITY OF RHODE ISLAND

1995 


\begin{abstract}
This thesis addresses the problem of the essence and mode of existence of the objects created by sentences found in literary works. In other words, it addresses the question, "Are there such things as fictional objects, and if so what kind of being do they possess?" It investigates whether the meanings of the words and sentences used to produce fictional objects, and these objects themselves, are real, ideal, purely psychic or have another distinct mode of existence; and if the latter, it shows that these meanings or their objects have more objectivity than purely imagined objects. It addresses the question of what consequences there are in holding various positions on the ontology of word and sentence meanings that are used in the creation of fictional objects. It also analyzes the type of logical structure and nature fictional objects possess, making use of insights gained from Roman Ingarden.
\end{abstract}




\section{ACKNOWLEDGMENT}

I would like to like to take this opportunity to thank the many people who have been instrumental in my bring this thesis to completion. First of all, I thank my original major professor, Dr. Mark Roberts, who opened my eyes to the different possibilities for a thesis topic and who aroused my interest in Roman Ingarden and his theories. Next I thank Dr. Fritz Wenisch who willingly took Dr. Roberts' place as my major professor. His encouragement, suggestions and support were invaluable to me. I thank Dr. Stephen Schwarz and Dr. Ira Kuhn for being on my thesis committee. A thanks goes to Dr. Richard Bailey for chairing the defense. I thank my Uncle and Aunt, Al and Judy Urbanski, for putting me up in their home which allowed me to formulate my thesis. I thank my sister Mary Jo Klein and her husband Darryl who took me in for a month after my stint in California. My sister who is a philosopher in her own right was an inspiration and comfort to me at the time I needed her the most to help me redirect myself and finally finish the thesis. I of course thank my mother Lia Brzozowski whose prayers, concern and love for her son enabled me to successfully complete my MA. Her love of knowledge also has been a constant reminder of where my own love originated. A special thanks goes to all my friends in R.I. who took me in freely sharing their hearts and hearth with me: Mrs. Lucille O'Dowd, Andy \& Abby Tardiff, Charlie \& Genevieve Kineke, and John \& Anna Doyle. You have all been a great blessing to me and I thank you again for sharing your lives with me. 
The Topic: Fictional and Imaginary Objects

The Common Understanding of Fictional Objects

Things We Take for Granted

To Be or Not To Be

Fictional Objects Cannot Be Identified with the Collection of Words or Sentences Used To Describe Them

Three Possible Solutions

They Have No Being

They are Purely Mental Entities

They are Extra-Mental Entities

II. THE FIRST POSSIBLE SOLUTION CONSIDERED

A "Prelude": Problems with Reference

What Is Reference?

Is There Reference to Fictional Objects?

Russell's Answer: No

Crittenden's Criticism of Russell

Crittenden's Solution: There Is Reference to Fictional

Objects, but Still, They Are Nothing

Some Critical Comments on Crittenden

Response to Russell and Crittenden

Where Russell Is Correct

Where Russell Is Wrong

Where Crittenden Is Correct

Where Crittenden Is Wrong

The Failure of Non-Being as the First Solution

III. THE SECOND POSSIBLE SOLUTION CONSIDERED

Evidence Against this Thesis

There Is Inter-subjective Agreement

Speaking about Fictional Objects Is Not Speaking

about Anyone's Mind

Whose Mind Is the Object In?

Multiplication of Fictional Objects? 
The Nature and the Mode of Existence of Words, and

Considerations Showing Their Difference from Their Meanings

Words and Communication

Sentences and Meanings - Where or How Do Meanings

Exist?

Meanings As Neither Real nor Ideal

Meanings As Intentional

Types of Intentional Objects: Original Purely Intentional

Objects and Derived Purely Intentional Objects (Also

Called Fictional Objects)

Derived Purely Intentional Objects

Derived Purely Intentional Sentence Correlates

Necessity of Intentional Objects

Ontically Autonomous vs. Purely Intentional

Quasi-Real Fictional World and Its Realities

Ideal Concepts Needed for Intersubjective Identity of Sentences 


\section{INTRODUCTION}

\section{The Topic - Fictional and Imaginary Objects}

This thesis will address the problem of the ontology of fictional objects. In other words, it will address the question, "Are there such things as fictional objects, and if so what kind of being do they possess?"

Fictional objects are those types of objects that have been created or conceived for use in works - written or spoken - such as novels, plays, poems or epics. They include persons as well as a variety of non-personal objects ranging from Hamlet's dagger to Odysseus' ship. They do not include those chimerical creations which remain limited to our own personal imagining or dreaming - to be called imaginary objects - unless, of course they become used specifically for some literary, aesthetic, or informational purpose. All fictional objects originated as imaginary objects but not all imaginary objects become fictional objects.

\section{The Common Understanding of Fictional Objects}

In everyday life we talk about fictional characters (which are a specific type of fictional objects) as if they existed in the way our friends and neighbors do. People in lunch rooms can often be overheard discussing the sex lives of characters in their favorite soap opera, and students of literature often debate the psychological turmoil that someone like Raskalnikov is going through. Public figures at times even comment on the morality of characters in various sitcoms. We also ask each other questions about such characters. Consider, 
for example, Hamlet the Prince of Denmark. We can ask: What type of person is he? With whom does he live? What are his likes and dislikes? How does he live his life? Is he concerned with improving himself morally? All these questions can be answered by either reading the play about him or talking to someone who has read it. Then one could know the answers or at least determine the relevance of these questions. ${ }^{1}$

We have an idea as to what type of an individual Hamlet is from reading the play about him. Still our common understanding of Hamlet is that he is just a fictional figure who does not really exist. This can be seen if someone started to ask questions such as, "You say Hamlet lives in Denmark, yet why can't I find his name in this book on the History of Denmark?" And we would reply that Hamlet is a literary figure created by Shakespeare as found in his play called Hamlet. Hamlet the Prince of Denmark as created by Shakespeare is not someone who has existed, is existing or will ever exist.

\section{Things We Take for Granted}

It seems, however, that there are things we never question in our everyday conversations about fictional characters as heard from academic halls to lunch rooms. We never really ask or think about

1 There appear to be certain questions that do not make sense when one talks about fictional objects i.e., future occurring events in different contexts. For example: "Are you going to meet Hamlet?" or "Have you met him?" when one means precisely the fictional character. 
questions such as, "What type of being do fictional characters have?" We just seem to have some foggy notion that, "No, Hamlet doesn't exist and yet I do think about him - I've even wondered how I would have acted if placed in his situation. "But how can we say that he doesn't exist and yet that we have thought about him? It seems that fictional objects like Hamlet must exist in some way, since we do talk and think about them.

\section{To Be or Not To Be}

Let us ask the question then: Do fictional objects exist in some way and if so what type of being do they have exactly? We say that Hamlet is a fictional object; but is this to say that he exists or that he does not exist? Do fictional objects have no being whatsoever? Or do they exist in our minds as some memory or idea that we call into being when we think of them? What are we actually talking about here? It does appear that we can initially make a distinction between something that is real such as this paper you are now reading and a mirage which is something that is not real and yet does have some type of existence or mode of being. But is a fictional object something just like a mirage or fantasy or dream? The answer seems to be negative, for there seem to be some things one is able to do with fictional objects, but not with dreams. One can, for instance, share one's novel with a friend, thereby possibly causing him/her to feel the same type of emotions one has experienced oneself, whereas one 
cannot just give people some drug, for example, so that they can experience the same dream that one had last night. ${ }^{2}$

\section{Fictional Objects Cannot Be Identified with the Collection of Words or Sentences Used To Describe Them}

A brief reflection upon the nature of Hamlet also makes it obvious that he is not the collection of words and sentences used to describe him because when we argue about Hamlet, we do not talk about those words or sentences - we talk about Hamlet, the fictional character, as described by those words and sentences. Furthermore, if he were just the collection of words and sentences used to describe him then it would seem that there would have to be as many Hamlets as there are languages that could be used to speak about him. Even more, if Hamlet were the collection of sentences describing him, an other absurdity would follow: One would be faced with the situation of there being as many Hamlets as there are books that had collections of words and sentences used to describe him (not even mentioning all the problems that would arise with the existence of the magnetized markings found in tapes and compact disks).

2 I can of course tell someone about my dream and so the objects of my dream cease to be merely imaginary objects and become fictional objects. This is because the contents of my dream were used to tell a story about my dream. Imaginary objects originating in dreams or from pure fancy also become fictional objects when I tell someone about them even if only for purely informational reasons. 


\section{Three Possible Solutions}

It appears that there can be three possible solutions to the problem of whether fictional objects possess some kind of reality, and if so what type.

\section{They Have No Being}

The first is that they have no being whatsoever. They are nothing - they don't exist in any way. Those who hold this position do so because of their presupposition that anything that can be talked about or referred to has to be real. This is the view of Franz Brentano and the later Russell, for example. (Only Russell's version of this theory shall be considered, though.)

\section{They are Purely Mental Entities}

The second view is that fictional objects are purely mental entities. They have a type of existence in our minds. They are mere objects of consciousness, mental entities whose mode of existence is entirely dependent upon some mind who happens to think them. If there were no minds, they would not exist at all. Accordingly, someone like Hamlet would be an idea or image that I personally have before me in my consciousness when I think of him or read about him. I would give "life" or a type of being to the fictional object by having the idea or image of him in my mind. (Juliusz Kleiner and E. Kucharski I believe 
could be considered representatives of this view although actually this view is more a logical consequence derived from maintaining that a literary work is identical with the psychic experiences of an author or reader.) On this view, the "mode of existence" of fictional objects would be the same as that of merely imaginary objects (objects of my personal and solitary imagining or dreaming).

\section{They are Extra-Mental Entities}

The third view is that fictional objects are extra-mental entities. Naturally, they depend on the mind in some ways, but do not exist in the mind; rather, they transcend ${ }^{3}$ it. They are objects that go beyond both the written text describing them as well as the minds of those people who happen to read and think about them. Philosophers subscribing to this position hold it because of various problems resulting from the view that fictional objects are just mental entities. Roman Ingarden holds this third view.

3 By the term "transcend" is meant something that is extra-mental but still mind-dependent as opposed to mind independent. This will be further discussed below. 


\section{THE FIRST POSSIBLE SOLUTION CONSIDERED:}

Let us now consider the first possible solution to the problem of whether fictional objects have being, and if so what kind of being they have. According to it, the answer to this question is that fictional objects have no being at all. This position is held, for example, by the later Russell, because he seems to think that otherwise, he would be committed to the uncomfortable position of asserting the existence of objects that do not exist. Russell was confronted with this problem when considering sentences such as, "Square circles are heavy." Whoever says this seems to refer to an object that is both heavy and a square circle. If one further assumes with the philosophers to be discussed here that wherever there is reference, what is referred to must exist, but that square circles obviously do not exist, we would have the apparent existence of a non-existing object.

\section{A "Prelude": Problems with Reference}

Those who hold the position that non-real objects do not have any being are led to this view because of problems they see connected with the assumption that reference to fictional objects (or any variety of imaginary or absurd or contradictory objects) occurs when talking about them. Therefore, we need to explain briefly what reference is and what it is that refers. This must be done before going into a further analysis of the first answer to this problem as put forth by Brentano and further developed by Russell. 


\section{What Is Reference?}

It has commonly been held by a number of philosophers starting with Plato and all the way up to Brentano, Russell, Quine, Strawson, and Searle that whenever language refers to something, that thing exists.

How is it possible to make a true statement about a nonexistent object? For if a statement is to be about something that thing must exist, otherwise how could the statement mention it, or refer to it? One cannot refer to, or mention nothing; and if a statement cannot be about nothing it must always be about something. ${ }^{4}$

We take the word "referring" here to mean that mental act people perform whenever they connect language, specifically by the use of meanings expressed through words and propositions expressed through declarative sentences, with objects and states of affairs in the world.

As to the question of what actually does the "referring," it is the meanings of words and sentences used by people to talk about objects or states of affairs. For example, the word "dog" has a meaning that refers to an object. It is the meaning of the word that refers to the

\footnotetext{
${ }^{4}$ Leonard Linsky, Referring (New York: Routledge and Kegan Paul, 1967), 122.
} 
object; the word merely expresses the meaning. Similarly, with a declarative sentence such as, "It is raining outside," it is the proposition (i.e. the meaning of the declarative sentence) that refers; in this case a state of affairs is referred to.

\section{Is There Reference to Fictional Objects? \\ Russell's Answer: No}

As mentioned, Russell states, in answer to the question of what type of being fictional objects have, that they have no being whatsoever. They appear to be objects but in fact do not exist in any way, and when their supposed "existence" is seen correctly one can show that they are really nothing at all. ${ }^{5}$ His theory of descriptions also called "paraphrase theory" because, as we will see, Russell claims that statements about fictional objects are to be replaced by a paraphrase revealing the falsity of the original statements - shows that Russell thinks reference to be always to something that is real. If there is reference then of course there must be an object referred to. If, however, one held that there was reference to something that does not exist one would be placed in the paradoxical position of saying that an object does not exist while at the same time asserting the existence of that object: This would mean that one would be talking nonsense.

5 The early Russell did believe that non-existent objects had to have some type of being as this allowed one to deny they had existence. See Linsky, Referring , 2. 
In response, Russell argues: When presented with an apparent reference to something that one knows does not exist, and an ascription of attributes to it, such as in, "The present King of France is bald," one only seems to be referring to a non-existent object; in truth, however, one is not. Rather, Russell asserts that the original statement needs to be replaced by a paraphrase and that this paraphrase shows the impression that one is referring to a nonexistent object to be mistaken. For the "King-of-France-example," Russell gives as a paraphrase, "There is one and only one present King of France and he is bald." This paraphrase asserts the existence of an actual current King of France. It is clearly the case that there is no present King of France and so he cannot have any attributes because he does not exist. Thus, the paraphrase is false. ${ }^{6}$ Since this new proposition is, according to Russell, merely a paraphrase of the original one, and since in the case of this new proposition, there is nothing the proposition would refer to (which makes the proposition false), we can now see that in the original proposition, there is no reference to a nonexistent object either; all there is is just a false proposition. What we really have when there is an apparent reference to a non-existent object is just a false assertion claiming that an object like the present King of France does in fact exist, and that he has certain properties.

6 Dr. Mark Roberts pointed out to me the fact that in this paraphrase there are actually two propositions. I assume he means: "There is one and only one present King of France." and "He is bald." I gather from this that it is more accurate to say the original proposition contains a false proposition within it. 
According to Russell, then, all one needs to do is to analyze those problematic propositions carefully, express their true meaning through his technique of paraphrase, and then discover that they are simply false.

\section{Crittenden's Criticism of Russell}

Charles Crittenden, in his work UNREALITY: The Metaphysics of Fictional Objects, analyzes Russell's solution to the problem of the mode of existence of fictional objects. He maintains that this solution may be adequate when one is dealing with propositions used as examples in philosophical discussion, but that it is inadequate when it is used to deal with literary creations. In other words, Crittenden does not criticize Russell's example, just its application to literary figures. Crittenden holds that when one is presented with a sentence such as, "The chief cyclops lives in a cave," one understands this as a true statement about a character in the epic poem the Odyssey. And so, according to Crittenden, a more correct interpretation of the proposition would have it preceded by the operator, "In the Odyssey the chief cyclops lives in a cave." Using the paraphrasing technique of Russell's theory, one would restate it as, "In the Odyssey there is one and only one chief cyclops and he lives in a cave." It is obvious that the proposition, "there is one and only one chief cyclops and he lives in a cave," is false, because it asserts the existence of the cyclops. While Russell would agree with this, he would, however, have to hold that the following statement is true: "In the Odyssey there is the false claim that there actually exists a chief cyclops, and that he lives in a 
cave." But as Crittenden points out, this is not the understanding we normally have when reading a literary work. Under the dictates of Russell's theory we would have to be reading it as false history or bad journalism. Further, we would not be able to enjoy our participation in the story if we viewed it in this way and so no one who has an understanding of literature does read or understand it in this way. ${ }^{7}$

Thus, according to Crittenden, all theories which attempt to paraphrase away expressions which make reference to fictional objects encounter one of two problems:

either there is a conflict between the truth values of the initial sentences and their claimed paraphrases, or the paraphrases are about something other than what the initial sentences are about. 8

7 Charles Crittenden, UNREALITY The Metaphysics of Fictional Objects (Ithaca, NY: Cornell University Press,1991), 23-26.

8 Ibid., 30. Applying Crittenden's view to "The chief cyclops lives in a cave," and the paraphrase: "There is one and only one chief cyclops and he lives in a cave." the first proposition would be true according to Crittenden and the second proposition false. Thus we show a conflict of truth values. The second problem also appears in the example as the paraphrase is about something other than what the first proposition is about. The first proposition says something about a character within a literary work whereas the second proposition says something about whether this character exists in actual or empirical reality. 
With this, Crittenden has shown that Russell is incorrect when his theory of descriptions is applied to literary creations.

\section{Crittenden's Solution: There Is Reference to Fictional Objects, but Still, They Are Nothing}

Concerning Crittenden's own solution to the problem of whether there are such things as fictional objects, he claims to show that reference to fictional objects does in fact occur. In order to show this, he makes an important distinction. It can be seen if on the one hand, we consider the statement, "Sherlock Holmes smokes a pipe"; and on the other hand statements like, "Sherlock Holmes is my favorite fictional detective," and "Sherlock Holmes was created by Arthur Conan Doyle." The first example can be verified by someone who has read a novel about Sherlock Holmes. It belongs to a class of statements which one can begin with, "in the story/novel/ myth..." Crittenden calls such statements "inside" statements, and designates the content of the story as what makes them true or false. The latter two examples are statements making claims about fictional objects by giving them properties not found within the contents of a story but rather in empirical reality. And so their truth value is dependent upon their correspondence to empirical reality. Crittenden calls statements of this nature "outside" statements.

These examples of "outside" statements clearly show that reference to nonexistent objects does in fact take place. For they cannot be paraphrased away as being just false statements affirming 
the existence of objects which in fact do not exist. Even if Russell could convince us that, "The present king of France is bald," is just a false statement, whoever says with conviction, "Sherlock Holmes is my favorite fictional detective," would be dumbfounded if someone would try to make him believe that his assertion was false. Clearly, we are confronted with a true statement. Thus, since it is impossible in this case to explain the reference function away by unmasking the original statement as false, clearly, reference does in fact occur here. Thus, the question whether there is reference to fictional objects has been answered: In the case of the so-called outside statements at least, we are dealing also with genuine cases of reference to fictional objects.

However, Crittenden also believes that reference occurs within a literary work. His analysis of the referring function of "inside statements" seems, however, unclear - even contradictory. For what he calls "inside" statements would really have to be outside ones for two reasons: First, as soon as one pulls a sentence out of a story and introduces it with the phrase, "in the story" (or with similar phrases), one has turned a so-called inside statement into an outside one, as the sentences occurring in the story do not begin with this phrase; rather, it is always someone outside of the story who makes the determination of whether or not some "object" of a so-called inside statement has the properties ascribed to it by comparing the statement to the text which exists in the real world. Second, one can have truth or falsity only when there is some type of correspondence between a belief and something outside of the belief itself, that is, a state of affairs objectively separated from the belief. Crittenden, however, seems to hold, for inside statements at least, a coherence theory of 
truth as opposed to any type of correspondence theory as can be gleaned from his statement: "Storytellers' sentences are not used to make claims about independently existing states of affairs but to construct a fictional situation... [S]entences appearing in the text of a novel have no truth value and themselves serve as criteria for the truth-values of assertions [statements] about the contents of the novel".9 Yet Crittenden holds that inside statements have truth conditions but that this only occurs when one places the phrase or operator "in the story" in front of the statement. The point to be made here is that in examining an inside statement, with its operator, such as "In the story, Sherlock Holmes smokes a pipe," one realizes that the referent of the statement is not Sherlock Holmes but the actual text of the novel itself. This shows that reference to fictional objects is not made with inside statements when they have their operator attached to them. Thus, Crittenden's claims to the contrary not withstanding, on the basis of his assumptions, genuine reference to fictional objects seems to occur only with outside statements.

Even though Crittenden has shown that genuine reference to fictional objects does in fact occur, for him, this does not entail, however, that these objects have being of any type which is beyond that of a purely conceptual or grammatical object (for Crittenden a grammatical object is an object of reference, an object qua referred to). He holds that fictional objects have their own particular status, that they belong to their own conceptual category. It is just an accepted fact that in common discourse we make reference to fictional objects

9 Crittenden, UNREALITY, 91. 
without giving them the status of actual tangible existence.

Crittenden uses the examples, "Sherlock Holmes smokes a pipe," and, "Sherlock Holmes does not exist." 10 Here we have two sentences that express true propositions. This is because of the unique conceptual status Sherlock Holmes has. He is a fictional object so ipso facto he does not exist but at the same time because he is a member of the unique class of fictional objects we can make genuine references to him. This is because sentences ${ }^{11}$ have been created by an author in the context of telling a story. Crittenden holds:

Like direct objects, fictions are purely intentional, having no status in existence at all. ...There are such objects solely in the sense that they have been written about and thereby become available for thought or reference. ${ }^{12}$

and:

10 This is certainly a problem for how can Sherlock Holmes not exist and yet it be true that he is a pipe smoker? The problem as Dr. Mark Roberts pointed out to me is not that properties can be given to a fictional object but that a proposition expressing these properties as attributable to a fictional object can be true.

11 It is more correct, as we will see in later sections, to say that sentences and their meanings have been created by an author. Crittenden, however, does not make the distinction between sentences and their meanings.

12 Crittenden, UNREALITY, 65. 
Intentional objects are objects of thought, items qua thought about; grammatical objects are objects of reference, items qua referred to. An intentional object can fail to be a grammatical one through there failing to be a sentence about it. But all mere referents are intentional objects, for reference includes thinking of the intended referent. 13

\section{Some Critical Comments on Crittenden}

Using his class of outside statements discussed earlier, Crittenden seems to have shown that reference to fictional literary figures does indeed occur. What he has not adequately shown is that reference does also occur with what he calls inside statements. Moreover, even if we were to grant him that he has shown reference to occur in the context of inside statements, he still holds that fictional objects are nothing. As will be shown, this position seems to be mistaken.

Further, when discussing the role of an author in creating a story Crittenden says that an author both introduces an object and calls a reader's attention to it and that this is a double process in which reference is taking place. But how can there be reference to a fictional object unless the object is first constructed? It is only after this

13 Ibid., 66. Intentional objects can be looked on as being imaginary objects (see my earlier distinction, page1) and grammatical objects as fictional objects. 
construction that one can refer to the object. How can a sentence that has the function to construct a fictional world at the same time be making reference? That the sentences in a novel as they are being written out make reference to some object that is not even yet presented seems to be questionable at best. Moreover, if some fictional world is being constructed, not only does one need to ask, "How can there be true reference to it unless it is first described," but also, "How would one know whether the impressions one has had about the fictional world were correct until the fictional world was fully presented?"

\section{Response to Russell and Crittenden: Where Russell Is Correct}

Russell is correct in holding that reference must always be to something that exists; it is, after all, just a logical truth that if one were able to talk about a fictional object one would have to have something which is present for that discussion to take place.

\section{Where Russell Is Wrong}

Russell is wrong however in holding that reference does not occur when one is dealing with fictions. We have shown that Russell's theories are not adequate responses to the problem of what type of being fictional objects possess. 


\section{Where Crittenden Is Correct}

Crittenden appears to have successfully shown that there is reference to fictional objects. I don't see how one can deny that reference to a fictional object takes place when one is presented with a proposition such as, "The cyclopses are the most terrifying creatures found in Greek literature." One may disagree and think that Proteus or the seven-headed Hydra are more terrifying, but the fact that such statements are understood and can be debated proves that reference to fictional objects has occurred.

\section{Where Crittenden Is Wrong}

Crittenden is wrong, however, in holding that there can be reference to non-being. The very fact that one has reference to "something," in this case to a fictional object, shows that something must be present which is the object of one's reference. It is not possible to assert that there is reference and then to say that it is to nothing. But this is exactly what Crittenden seems to do.

\section{The Failure of Non-Being as the First Solution}

Therefore, we can now see from all that we have done above in analyzing the ideas of Russell and Crittenden that the theory that fictional objects are nothing at all is false since there is reference to them. We do have genuine reference to fictional objects and this has established the fact that there are such things as fictional objects. 


\section{THE SECOND POSSIBLE SOLUTION CONSIDERED:}

Now that we've seen that fictional objects are not nothing, let us consider the second possible solution, namely that they are purely mental entities; entities that are mere objects of consciousness mental entities whose mode of existence is entirely dependent upon some mind who happens to think them. In this section I will try to refute this view that admits that there are fictional objects but reduces them to purely mind-dependent entities. One needs to make a distinction, however, between something being purely mind-dependent and something that may be mind-dependent in its initial creation, but subsequently also have some type of extra-mental existence. The view that I am addressing here is that fictional objects have no extramental existence whatsoever, that they are strictly limited to being "correlates" of some mind experiencing them.

This view is held by all those who adhere to psychologism. Psychologism is the view that everything we know or think we know is just a mental construct of one form or another. Accordingly, truth is to be established only through purely subjective elements derived from self-observation. One consequence of this view is that, since all mathematical and logical laws are ultimately seen as being minddependent, so are all mathematical and logical truths. But is it really the case that $2+2$ did not equal 4 until someone thought up the equation, or that the law of non-contradiction, for example, was not operative until Aristotle formulated it? These types of criticisms were effectively used by Husserl to refute psychologism in all of its forms.

One does, however, not need to be a psychologist to hold that fictional objects are purely mind-dependent and have no extra-mental 
existence whatsoever. Let us now look into the evidence against this thesis.

\section{Evidence Against this Thesis:;:}

\section{There Is Inter-subjective Agreement}

Although fictional objects depend upon a mind for their initial creation, they must transcend the mind; for when people are heard discussing some fictional character, there can be inter-subjective agreement about the character, proving that fictional objects transcend the mind. If they were only in the mind, each person would have his or her own understanding which could not be communicated to other persons. But it is an undeniable fact that there is communication; therefore, a fictional object is not purely mind-dependent: If someone like Hamlet only existed in one's memory or imagination, how could there be any real agreement among people, since no one can jump into the mind of another to experience that object? When two people communicate there is some referent which is used as the common starting point of that communication. In the case of a fictional character referred to by a text (more specifically the many sentences which build up and define the character) we can compare our idea of the character with the actual description and attributes of the character as found in the text. The text becomes the final arbitrator for the correctness of our understanding. 


\section{Speaking about Fictional Objects Is Not Speaking about Anyone's}

Mind

Another argument against the thesis that fictional objects are purely mind-dependent is that when one talks about a fictional object such as Hamlet one does not talk about one's own mind nor the mind of the person one is speaking with, nor does one talk about the mind of the author who originally created him (since after all he may be dead). One does not study the mind and its mental actions or make reference to the mind and its mental actions when speaking about Hamlet. One does not focus attention on any mental act but rather on the subject under discussion, i.e. specifically Hamlet. It is, however, necessary for the mental act of reference to occur when one talks to another about Hamlet.

\section{Whose Mind Is the Object In?}

A third argument against the view that fictional objects are purely mind-dependent entities is that if fictional objects were purely mental entities then for any true statement made about a particular fictional character one would have to know whose mind one is referring to in determining whether the statement is true. And this is clearly not the case, as we can be confronted with any number of propositions about Hamlet without knowing whose mind created them in order to come to some understanding about Hamlet. 


\section{Multiplication of Fictional Objects?}

There is another absurdity following from making the mode of existence of a fictional object purely mind-dependent as opposed to extra-mental even though mind-dependent in the object's origin: There would have to be as many fictional objects as there are minds who think about them. Who really wants to hold that there are as many Hamlets as there are minds who have thought about him or who will think about him? Is it not the case that one can come to an understanding about who Hamlet is as a fictional character because we all have the same Hamlet in mind when talking about him or thinking about him?

Therefore I think we can safely say that fictional objects cannot be purely mental entities. 


\section{THE THIRD SOLUTION}

As we have shown, fictional objects are neither nothing, nor are they purely mental entities. Therefore they must have some being outside of the mind. But the question is, just what type of being could they possibly have? In this section I will show in what way fictional objects are extra-mental entities, mainly using the analysis and argumentation of Roman Ingarden.

Ingarden has shown in his book The Literary Work of Art that in order to understand the type of existence a "represented object" (i.e. fictional object in a literary work) has, one must first understand the nature of the entities which create the represented object, as well as the type of existence which those entities have. Ingarden, therefore, first brings us to an understanding of the type of existence the meanings of words have, since they are the basic building blocks of the meanings of sentences which in turn allow the build-up of complexes of meanings of sentences which are used to create fictional worlds or objects in those worlds. Thus, we need to ask first, "Just what is a word?" Next, we need to show that words are different from meanings; subsequently, an analogous difference between sentences and their meanings needs to be pointed out, and finally, the question needs to be asked, "What is the mode of existence of meanings?" 


\section{The Nature and the Mode of Existence of Words, and Considerations Showing Their Difference from Their Meanings}

The mode of existence of words and of sentences into which words can be combined seems to be easily accounted for: Both seem to be real entities in the real world around us.

A word is, after all, to be understood as a physical sign. These physical signs can be presented in two different ways, either as an audible sound or as a visible marking of some kind. But these physical signs are just that: signs which point to something other than what they themselves are.

And what they point to are meanings. That meanings are different from the signs used to represent them can be shown by the fact that one can have many instances of the same word and yet all those words point to the same meaning. One can also have the same meaning expressed in various languages such as the meaning of the word "love" expressed as it is in English as well as in Latin: "amor." We also have the cases of those words which express the same meaning in a language yet are spelled and pronounced differently. These are the synonyms such as "hit" and "strike" as well as "peak" and "summit." Clearly, as we have seen in these examples, the words differ from each other, but the meaning is the same, which shows an identification of word and meaning to be mistaken.

A further argument in support of the difference between words and their meanings can be derived from the peculiar instances where the same physical representation of the word is used but different 
meanings are associated with it according to the context that is used in a sentence. (It is only after a context is given that a particular meaning is actually expressed by the word.) I am thinking of those homonyms such as "bat" which can have the meaning of a strong solid stick made of wood with one end thicker or broader than the other used in baseball or the meaning of any variety of creatures who are the only mammals capable of true flight. Again, identifying the word and its meaning would make it impossible for the same word to have these totally different meanings.

There are also such words as "bare" and "bear" which have the same pronunciation or word sound and yet have a different spelling and meaning.

If these words were written (as in the case of the former pair) or spoken (as in the case of the latter pair) by themselves and not in the context of other words we would never be able to tell what meaning they have.

\section{Words and Communication}

Individual words are used in order to communicate our thoughts, not only to others, but also as a record for ourselves. It seems that in communicating with others we seldom use only one word. We usually communicate by the use of subject, verb, and object type sentences. An exception to this seems to be words we use for commands or warnings such as "Stop!" or "Fire!" But even these upon closer inspection reveal that they are a type of uniquely imbedded sentence as revealed by the fact that an exclamation point is used to express 
urgency or admonition. Also, in order to be of any use in communicating some idea which would produce an action or change in action, these unique "words" need to be directed to some individual or group of individuals, such as in, "You there, in the blue shirt, Stop! a car is coming" or "Everyone in the theater - Fire! Get out!", although only the word "Stop" is spoken in the former example and "Fire" in the latter example. We do have the example of a word such as "Hello" which functions both as a word and as a sentence. (In order for this word to function as a sentence it has to be directed to someone and even though it doesn't have an exclamation point when written down we can tell its particular function by the fact that we capitalize the first letter when it is used as a sentence and we do not capitalize it when making reference to it as just being a word of the English language ${ }^{14}$ ). Still, ordinarily, when we communicate with others, or at least intend to communicate with them, we use individual words in combination with other words (most often explicitly but sometimes implicitly as in the above examples).

\section{Sentences and Meanings - Where or How Do Meanings Exist?}

We have seen the difference between words and their meanings; now we need to show the difference between sentences and their meanings.

14 Roman Ingarden, The Literary Work of Art, trans. George G. Grabowicz (Evanston, Illinois: Northwestern University Press,1973), 108. Ingarden is quoting A. Marty. 
The difference between sentences and their meanings can be shown through arguments similar to those used to show that words are different from their meanings. For example, one can have two different (synonymous) sentences expressing the same meaning, such as, "The man is driving around in his car," and, "The man is riding around in his automobile." One can also have two equal sentences each having a different meaning depending upon the context they are spoken in. For example, "Please pick up that bat and give it to me," spoken on a baseball field has a different meaning from, "Please pick up that bat and give it to me," spoken in a biological research laboratory. Again, since different sentences can express the same meaning, and the same sentence can express different meanings, it is mistaken to identify sentences and meanings.

Meanings appear to be able to "transcend" the words that express them, and so they are different from the words and word sounds used to express them. But where do meanings exist? In the minds of individuals of a particular society or somehow in the collective consciousness of some society or of humanity as a whole? This question is not addressed by Ingarden but he does have an answer as to what type of existence meanings have.

\section{Meanings As Neither Real nor Ideal}

We have seen that the type of existence that words and sentences have is easily accounted for. We have also seen that words and sentences are different from their meanings. We have not yet shown, however, what type of existence meanings have. 
meanings of words and sentences were ideal, the objects created or projected by them would also have to be ideal since they would rest on an ideal foundation. If meanings are ideal then the idea of someone like Hamlet or even Donald Duck had to have existed for all time (just like the idea of a triangle) since the complex meaning units used to create them existed for all time and so they were just waiting to be discovered by some literary adventurer. This does not seem to be the case at all although meanings can refer to ideal objects such as the concept of a perfect triangle.

If, therefore, meanings of words and sentences do not seem to be either real or ideal ${ }^{16}$, then what type of existence do they have? We have shown that they are not purely psychological entities existing only in the minds of those who happen to think them, since we do not refer to the mind of the author or reader when we reflect on the

brought into being by subjective acts of consciousness (mental acts) which bind various meanings to words. But the putting together of these meanings to form complexes of meanings is a truly creative act in which authors participate. However, he also seems to hold the position that one makes use of concepts in bringing meanings into being (which are like essences in that they are ideal). And one makes use of many slightly different meanings which reflect different aspects of an ideal concept in the creation of a literary work. See last section of this paper: Ideal Concepts Needed for Intersubjective Identity of Sentences.

16 I cannot go into the question whether this holds for all meanings. It does, however, seem to hold for all meanings used in a literary work. 
meaning of a word or sentence. We seem to be stuck, though, because of the problems involved with both possibilities referred to above; thus, the status of word and sentence meanings seems to remain in a sort of limbo between the poles of being real or ideal.

\section{Meanings As Intentional}

Ingarden's solution to this problem is that the meanings of words are purely intentional in their mode of existence. An intentional object is the referent of our thought. But objects of thought can be either simple or complex, just as meanings can be simple, as in one meaning expressed by a word, or complex, as in a variety of interdependent meanings expressed by sentences explaining or building up a fictional world.

Since words are the basic building blocks used to create sentences, and since the objects projected by word-meanings are purely intentional, the objects and state of affairs projected by the meanings of sentences must also be purely intentional in their mode of existence.

Ingarden holds that every sentence has what he calls a purely intentional sentence correlate. Purely intentional correlates of sentences are actually the states of affairs projected by the meaning units of the words that comprise the sentences. Meanings of words as well as of sentences, according to Ingarden, may be initially dependent upon certain mental acts for their creation in our minds. Meanings of words and sentences also are initially dependent upon certain other mental acts which must produce the physical word-representations 
(i.e. the audible or written word); but once this has occurred, these meanings come to be mind-independent inter-subjective entities. This can readily be seen if one thinks of all the ways we have of communicating novels and plays such as our use of printed matter, laser disks, audio tapes etc.

The meanings of words as well the meaning units of sentences are what one understands. A word is tied or bonded to a meaning by a mental act. For words are only intelligible if one understands the meanings that have become associated with them. It is the meanings of words which have the important function of projecting the objects they represent. Most often various meanings need to be used with other meanings to complete the projection of an object. For example the meaning of the word "dog" projects an incomplete object, as does the meaning of the word "black"; but when placed together we have a more specific projection of "black dog" although this is still incomplete as we do not yet know what type of dog is being referred to. However, it is the objects projected by individual words as well as the states of affairs projected by the meaning units of sentences which one focuses upon. The understanding of the meaning and the focusing upon the object occur simultaneously. Anyone can understand the meaning of words or sentences as long as he understands the language in which they are expressed. So meanings are what one uses to understand those entities (whether they be objects projected by single words or objects as components of states of affairs as well as the states of affairs themselves projected by sentences) that become intersubjectively present. 
Every sentence has, according to Ingarden, an intentional sentence correlate, and for the declarative sentence, this correlate is an intentional state of affairs projected by the meaning units the sentence expresses. States of affairs can exist only in two ways: either as purely intentional or as objectively existing. Only sentences which express true judgments (the meanings of the sentences would be called propositions) have purely intentional sentence correlates that correspond to objectively existing states of affairs. All other purely intentional sentence correlates are projected by meanings and have no correspondence to any other objectivity.

\section{Types of Intentional Objects: Original Purely Intentional Objects and Derived Purely Intentional Objects (Also Called Fictional Objects)}

Ingarden distinguishes between originally purely intentional objects and derived purely intentional objects.

The former are those entities created by a conscious being without attempting (yet) to communicate them to other conscious beings. These entities are strictly personal as they reside in the consciousness of the individual who creates them. A character I am thinking of for possible use in a parody of a poem I have not written yet would be an example of this.

Derived purely intentional objects on the other hand are those entities which contain a borrowed intentionality that resides in the intentionality of the meaning units used to create them and only indirectly in the original intentionality of some conscious creator. 
Derived purely intentional objects then are freed from the subjective confines of any one individual consciousness and are able to be intersubjectively present to any number of individuals who can then identify them as being identically the same. My writing out the poem I thought of and submitting it for publication would cause the character thought of to become inter-subjectively present, that is, to become a derived purely intentional object.

Strictly speaking, a fictional object is a derived purely intentional object of a specific type. ${ }^{17}$ We can say that a fictional object has more objectivity than things that are just purely imagined. Things or people or places that we did imagine only exist as a referent of our past thoughts in our memories; unless we express those ideas in some physical form, e.g. write them out, what type of existence can they be said to have? They cannot be shared with others and so there is no inter-subjective reality which people can refer to and analyze. On the other hand, I'm sure we have all had the experience of reading some novel and strongly disagreeing with the actor chosen for a stage play about it or with the way the novel was presented in a movie. Some friends might have thought that the representation was done correctly and one can argue with them because of the objectively existing novel to which one can make reference.

17 One could have any variety of derived purely intentional objects based on the type of object that is projected by the meaning units used to create them. For example one could write about mathematical objects, contradictory objects, historical objects etc. 


\section{Derived Purely Intentional Objects}

Ingarden distinguishes three aspects of a purely intentional object: A. its content, B. its intentional structure and C. its mode of existence. Since we are dealing with derived purely intentional objects (i.e. fictional objects) in this paper we will narrow the explanation of his analysis to derived purely intentional objects (except when original purely intentional objects need to be considered to come to a better understanding of intentional objects). To help make these concepts more understandable in explaining them let us take as an example the derived purely intentional object projected by the meaning of the expression: "a bear." To the content (A) of this object belongs: 1) the formal aspects of the bear, 2) the total range of material attributes qualifying the object as a bear while partaking of the formal aspects of the bear (these latter two categories, i.e. 1 and 2, can be looked upon as being analogous to the common distinction of an object being comprised of form and matter) and, 3) an existence of some sort. (This last category would only depend upon what type of existence was intended for the bear such as ideal, real, absurd, or fictitious, i.e. a story within a story, as when a fictional character in a novel mentions a bear as the subject of a fairy tale he had written.) The content of a derived purely intentional object has its own formal aspect as we have just shown but the main element of this formal aspect is that it functions as the carrier of the properties or features that determine the type of object in question. The intentional object as an intentional object also has its own formal aspect or structure (B) or, as Ingarden 
also calls it, its own "carrier" of its properties. To this carrier belongs the fact that it has a content (the bear in question, which as we remember has its own form, matter and existence (even if it is only ultimately an intended existence)). But what also belongs to this carrier is the fact that the intentional object is only "something intended." This latter fact shows the mode of existence (C) that all intentional objects possess is one of a purely heteronomous existence no matter what the portrayed existence of its content may be (the real or fictitious bear in question). ${ }^{18}$ (Heteronomous in the sense of having a mode of existence that is "merely assigned" or "merely intended." 19) And so we see that intentional objects have a peculiar "double-carrier" or "two-sided" aspect about them. (This aspect of intentional objects will have important consequences for understanding the nature of fictional objects as will be seen later in this thesis.) The intentional structure of any derived purely intentional object is dependent upon original acts of consciousness for its creation (my thinking or writing about a specific "bear"), but transcends those acts and is different from them because the purely intentional object precisely is intentional. Ingarden tells us, "The purely intentional object as such is, itself, a 'nothing' in terms of ontic autonomy ... in itself it can neither exist nor be capable of changing itself." 20 This is precisely because it is created by subjective conscious acts. He says also, "In comparison with any ontically autonomous object it is an 'illusion' ... that draws its illusory

18 Ingarden, The Literary Work, 118-120.

19 Ibid., 122 and 132.

20 Ibid., 122. 
existence and essence from the projecting intention (from the 'meaning-bestowal'...) of the intentional act." 21 I understand a meaning-bestowal act for Ingarden to be one in which either meaning is originally bonded to some word or meanings are built up through the combination of many different interrelated sentences. With this latter case, one would have meaning units which project a complex object such as the portrayal for example, of a particular bear with its own various personality traits coming to light from being in different situations etc. as opposed to the projection of just a simple single object occurring from the bonding of a meaning to a word as in the former instance.

\section{Derived Purely Intentional Sentence Correlates}

According to Ingarden "every sentence 'has' according to its own essence, a derived purely intentional sentence correlate." 22 This also includes even absurd and ambiguous sentences. Just as we distinguished three aspects of a purely intentional object, A. its content, B. its intentional structure and C. its mode of existence, so too do we need to do the same with intentional sentence correlates. To help make these concepts more understandable let us take as an example the sentence correlates, "Is the bear brown?" and "The bear is brown." In the content (A) of these correlates we can distinguish: 1) their matter, 2) their formal structure and, 3) an existence of some

21 Ibid., 123.

22 Ibid., 130. 
sort. The matter in these two examples are exactly the same if we hold that the same bear is being referred to in each example; however, their structures are different according to the types of correlates in question. The former example has the structure of that of a "problem" whereas the latter example has a structure of that of a "state of affairs." The ontic characterization or type of existence for our examples is that of "existing" for the state of affairs but only having the status of being "questionable" for that of the problem. These examples of course would need to be placed within a context of some sort so that one knew whether an ideal bear, a real bear, or a fictitious bear was intended. Ingarden distinguishes the aforementioned structure from the structure (B) of intentional sentence correlates themselves which have their own "carrier" of properties and features. The features are that of having a content of some intended sort i.e. real, ideal, fictitious etc. and the feature of only having a (C) merely intended existence (ontically heteronomous). This shows that intentional sentence correlates (just as intentional objects) have a peculiar "two-sided," "double-carrier" or "double property-structure" aspect about them. ${ }^{23}$ The importance of this aspect for understanding fictional objects will come to light in the following sections

\section{Necessity of Intentional Objects}

It seems obvious that if the meanings of words and sentences have a purely intentional mode of existence then there are many

23 Ibid., 130-132. 
objects or entities that are purely intentional. As was mentioned, according to Ingarden, every sentence "has its own purely intentional correlate"; we can infer from this that any object that any speaker or author would focus upon, be it a person, a state of affairs, an event etc., has a purely intentional existence. This holds for everything within fiction, of course, but also in some sense for all things outside of fiction. Things do really exist and have their own reality and autonomous mind-independent (not at all depending upon a mind) existence. But a real object I write or think about also has an intentional existence, that is, it is an intentional object precisely because I am writing or thinking about it. Usually we are not aware of another object and its intentionality when writing or thinking about a real object. Normally, we focus upon the real object, and its intentional object is, as Ingarden says, "transparent." We only become aware of the intentional objects when we may be mistaken or unsure about some judgment we are making about a real object or supposed real person, state of affairs, event, etc.

As was earlier pointed out, purely intentional sentence correlates are "two-sided." So are purely intentional objects. We made a distinction between their content and their intentional structure and mode of existence. Ingarden points out, "If one were not to do this, one would have to concede that purely intentional sentence correlates contain mutually contradictory elements... the purely intentional sentence correlate as such - precisely because it is intentional always has one and the same heteronomous mode of existence." 24

24 Ibid., 131. 
The content, as was pointed out earlier, can have ontic characteristics different from that of the purely intentional sentence correlate which is the purely intentional "carrier" of that content. The purely intentional sentence correlate as carrier can only have one mode of existence, that of heteronomous existence. An example of the contradiction Ingarden mentions that would occur if his distinction between intentional "carrier" and content of that carrier was not made is: It would appear that one was saying that an object could be both real (as in being created and not previously existing in space and time) and yet that it has just an intentional mode of existence.

\section{Ontically Autonomous vs. Purely Intentional}

Ingarden further points out that the criteria applying to the contents of purely intentional states of affairs are different from those which apply to ontically autonomous states of affairs. For example: 1) the latter must satisfy all laws that would arise from the nature of the objects that may make up such a state of affairs; i.e. all physical, chemical and similar laws must be obeyed; 2) they cannot contain mutually exclusive material elements; 3) they must be "completely, unequivocally, determined."25 All three of these points can be violated by purely intentional states of affairs. But before showing that this is in fact the case we need to analyze the ideas of Barry Smith. Smith states, "Ingarden was the first to point out fictional objects possess a

25 Ibid., 142. 
quite peculiar double property-structure."26 What Smith is referring to here is the "double-carrier" or "two-sided" structure aspect of purely intentional sentence correlates as found in works of literary fiction. "...Ingarden's suggestion is that we must develop a conception of fictional objects as radically distinct, in their property behavior, from real objects of the material world." 27

Smith uses examples that bring out and extend what Ingarden talks about theoretically. Smith does not, however, fall into the same problems that Crittenden had with his inside/outside distinction. Basing his ideas on Ingarden, Smith tells us that fictional objects are to be conceived as having two different types of properties: one rank of properties in the strict sense, the other more properly understood as having ascribed characteristics. ${ }^{28}$ [I take Smith to mean either ascribed explicitly by the text or derived by the reader from what is implicitly given in the text.] Smith says that two different types of statements can be made about fictional characters which correspond to the aforementioned two ranks. These statements each have what he calls a different kind of "truth-behavior." The first type correspond to what he calls A-statements. These include meta-level statements made about fictional characters of the type which "are to be found in critical and theoretical texts. (Examples would be: 'Sherlock Holmes was

26 Barry Smith, "Ingarden vs. Meinong on the logic of Fiction," Philosophy and Phenomenological Research, 100.

27 Ibid., 101.

28 Ibid., 101. 
presented in novel $\mathrm{N}$ as a violin-playing detective'...)."29 These Astatements can be unconditionally true or false and they will always satisfy the law of excluded middle. The second type correspond to what he calls B-statements. They are found within the works of fiction themselves, but they may also include those statements we can ourselves "...within certain limits... deduce by appealing to logical and scientific laws." 30 The first type of B-statements (which we would only be able to acknowledge as correct or incorrect if we metaphorically interpret the predicates) such as, "Sherlock Holmes was a detective," would be determined correct by simply appealing to the text although the fictional character "Sherlock Holmes" was not a detective in the narrow sense of the term since only real people may be detectives. Smith states that B-statements unlike A-statements fail the law of excluded middle. To explain what Smith proposes let us analyze two Bstatements of the second type violating a logical law: "Hamlet was lefthanded" and "Hamlet was not left-handed." One discovers each statement to be neither correct nor incorrect although their negations, "It is not the case that Hamlet was left-handed" and "It is not the case that Hamlet was not left-handed," are also neither correct nor incorrect.

Smith told us that there are other B-statements (the second type) which one can deduce from the B-statements (the first type) found within the novels themselves by appealing to logical and scientific laws. He does not give us an example of a scientific type but

29 Ibid., 100.

30 Ibid., 100. 
I assume he must mean something like "The detective Sherlock Holmes cannot walk through walls" as a correct statement of this kind as Sherlock Holmes is presented as being a nineteenth Century detective living in London. And I don't know of any nineteenth Century detectives who had such an ability to break the laws of nature as we currently know them. Now Sir Arthur Conan Doyle could have easily given Sherlock Holmes such a characteristic but that would have changed the type of realistic detective stories he had written to supernatural or science fiction detective stories.

As we have seen there are two types of B-statements, i.e., those found within the novel and those formulated after the existence of the former.

We, however, can be more precise concerning what Smith proposes as one can actually come up with varieties of B-statements of different categories of the second type (not all of which necessarily fail the law of excluded middle.) $)^{31}$ Before making our distinctions let us call B-statements of the first type (those statements found within novels themselves i.e. "Sherlock Holmes was a detective.") B1 statements.

Other statements which can be formulated from B1-statements will be numbered sequentially. By appealing to logical laws one can produce a B2-statement that does not violate the law of excluded middle, for example: "Hamlet is left-handed or Hamlet is not lefthanded." This is an example of a disjunctive statement which is

31 I am indebited to Dr. Fritz Wenisch for these insights into the varieties of possible B-statements. 
"logically true." If we could ask Shakespeare whether this was so he would presumably have to say it was a correct statement. It is just a logical fact that, as Hamlet was portrayed, he must have been either left-handed or not left-handed and so the disjunctive statement must be correct.

We can also come up with B3-statements that can be determined to be either correct or incorrect by appealing to scientific laws. For example, an author could be describing a scene taking place in Rhode Island and how it was snowing. That it was winter when the scene took place was never explicitly stated. If, however, someone made the B3-statement: "The scene from the novel took place during winter" we would know it to be a correct statement as opposed to the incorrect B3statement: "The scene from the novel took place in the summer." We could also produce any variety of B4-statements based upon biological laws as they were known by the author of some fictional work to determine whether they are correct or not. If, for example, we stated that: "Hamlet could die of AIDS" this would be an incorrect statement since AIDS was not around at the time of Shakespeare; however, if we stated: "Hamlet would be hurt if hit with a rock" one would have to concur that this was a correct statement. But the most interesting types of statements about fictional objects that can be formulated from B1-statements are B5-statements that have an undetermined nature as to whether they are correct or incorrect. They are those types of statements that if they and their negations were joined in a disjunctive statement, the latter would have to be correct. When, however, they are presented alone it cannot be determined whether they are correct or incorrect. Two examples of B5-statements are: "Hamlet is left- 
handed" and "Hamlet is not left-handed." Both statements are of a totally undetermined nature. If we could ask Shakespeare: "Is Hamlet right-handed?" Shakespeare could possibly say: "Well, the image I have of Hamlet when I think of him is as being right-handed although I've never really thought about it until you brought up the question."32 He could also say, "Well, I don't know - I have never thought of it." Shakespeare did not write about or portray Hamlet as being righthanded or left-handed regardless of what Shakespeare may have had in mind for his character. This illustrates the peculiar "ontological incompleteness" that fictional objects possess.

We have seen a variety of statements formulated from B1statements but it also seems possible to me that a particular novel could contain a pair of B1-statements having a contradictory nature. One could be presented in the first chapter with a character who is called left-handed. But, by the middle of the novel the character could be called right-handed. There are variety of reasons why this could occur. The first is that it was just an oversight of the author. The second is that it is part of the presentation of the novel itself and this too could be occurring for various reasons: It could be, for example, that some other character was mistaken or being deceitful; it could also be that the novel portrays some psychological or stream of

32 One of course could have actors who portray Hamlet as being right handed or left handed but we are talking about the fictional character Hamlet as found in the play Hamlet written by Shakespeare and not about the actors who portray him as being one way or the other. 
consciousness drama in which any number of contradictory type B1statements would be presented.

With the help of Smith we can now show, as was mentioned in the beginning of this section, how the contents of purely intentional states of affairs can violate the three criteria which autonomous states of affairs cannot violate according to Ingarden. Let us restate the criteria: 1) the latter must satisfy all laws that would arise from the nature of the objects that may make up such a state of affairs; i.e. all physical, chemical and similar laws must be obeyed; 2) they cannot contain mutually exclusive material elements; 3 ) they must be "completely, unequivocally, determined." To apply Ingarden's thesis let us analyze some examples of purely intentional states of affairs that do in fact violate Ingarden's criteria set for ontically autonomous states of affairs.

1. "The cow jumped over the moon." Here we have a state of affairs such that the nature of the objects that make up the state of affairs violate the physical laws of nature. 2. "The boy picked up the round square." Here we have a state of affairs which contains mutually exclusive material elements. 3. "Hamlet was left-handed." Here is a state of affairs such that we do not know whether the state of affairs in question even applies to Hamlet because we are never told whether Hamlet is right-handed or left-handed. This example shows us that a purely intentional object is not "completely, [and] unequivocally, determined." 33 We are often presented with characters who, while

33 Ingarden, The Literary Work, 142. 
being portrayed as being just like really existing people, nevertheless have what Ingarden refers to as "spots of indeterminacy."34

Thus, Ingarden has discovered that fictional objects are radically different from either real or ideal ontically autonomous objects. As was just seen, for example, real objects do not violate the law of excluded middle. Statements can be made about every real object such that it can be determined at least theoretically whether or not they apply to the real object. I either have some property A or I do not have the property in question. I am, for example, either right-handed or I am not right-handed. But as we saw in applying the same criterion to a fictional object such as Hamlet, if we say, "Hamlet is right-handed," or, "Hamlet is not right-handed," neither assertion is correct nor incorrect. 35 Thus, we have a violation of the law of excluded middle. It is not just a matter of not knowing what property Hamlet has and that logically if he is supposed to be represented as a normal human being he would be one or the other. But rather Hamlet, as projected by the meaning units expressed by the words and sentences the play consists of is not defined in either way.

As was previously mentioned, Roman Ingarden holds the position that what we call fictional objects are in reality purely intentional objects. He made a distinction between those objects as they are represented in literary works, which he calls derived purely intentional objects, and those objects created directly by the original creative

34 Ibid., 246-252 and 341-342.

35 If both were incorrect we would not have a failure of the law of excluded middle, but the law of non-contradiction. 
processes of an author "from concrete acts of consciousness effected by an ego."36 (Original purely intentional objects). The derived purely intentional objects owe their existence to various word and sentence meanings and because of this they "contain a borrowed intentionality." 37 They have of course their ultimate source of existence in the original intentionality of the acts of consciousness of some author.

Ingarden holds that in comparison with ontically autonomous objects purely intentional objects are an "illusion,"38 an illusion however that is not based in the ontic sphere of actually existing autonomous objects but rather "an 'illusion' that draws its illusory existence and essence from the projecting intention... of the intentional act. On the other hand, the purely intentional object is not a complete nonentity, a nonentity which has no point of contact or support in any sphere of existence."39

36 Ingarden, The Literary Work, 118.

37 Ibid., p. 118.

38 Dr. Fritz Wenisch holds that the word "illusion" as chosen in this translation (unlike its German equivalent) seems questionable at this point in that it involves thinking that something unreal is thought of as real. But when reading a novel we ordinarily don't think about what we are reading is real. I agree to the extent that it holds before picking up the novel but that once we do start reading it we need to suspend reality in order to enjoy the novel and in a sense to step into its world. 39 Ingarden, The Literary Work, 123. 


\section{Quasi-Real Fictional World and Its Realities}

A fictional world and its objects are built up by the meanings of sentences of various types, i.e. state of affairs, questions, judgments, commands etc. and Ingarden states that "every sentence 'has,' according to its own essence, a derived purely intentional sentence correlate." 40 What this means for a state of affairs is that for every declarative sentence, there is a purely intentional state of affairs which is created by the meaning content of the sentence. But Ingarden holds that only "Objective states of affairs can directly correspond, ... to assertive propositions." 41 and further that: "...the objects appearing in the purely intentional state of affairs, or the state of affairs themselves are characterized according to their mode of existence as, e.g., real, ideal, merely possible, etc., but they are not set [accepted] as actually existing in the ontic mode." 42 In other words a fictional work contains sentences which seemingly express truths about actually existing realities, but nevertheless, they are not accepted as nor are they ultimately intended as positing actually existing realities. Rather, they express realities which are only part and parcel of the world the work represents. "...[T]he corresponding purely intentional states of affairs or objects are only regarded as really existing, without, figuratively speaking, being saturated with the character of reality.

40 Ibid., 130.

41 Ibid., 129.

42 Ibid., 166. 
That is why, despite the transposition into reality, the intentionally projected states of affairs form their own world"43 (i.e. the fictional world reality as presented by the novel, story or poem).

For Ingarden, the following is an example of an action which, while being regarded as really existing, has only the appearance of really existing:

If a sentence is spoken by a represented [fictional] character as a judgment directed at another represented character, then, if the first character is truly judging and is sincere, this sentence is undoubtedly a judgment in the strict sense; but at the same time it is a judgment that is valid or true only in the domain of the represented world and in regard to the objects of this world and, finally, only for the represented characters speaking with each other. And indeed this is true regardless of whether it is an individual and particular or a general judgment. 44

Ingarden holds that there are various criteria which allow one to distinguish the sentences which express actual propositions from those sentences which only appear to express actual propositions making some sort of judgment about some state of affairs. The latter he calls quasi-propositions and quasi-judgments as they only appear to be actual ones. 45 Ingarden states: "...even sentences which have the form of assertive propositions can be modified in such a way that, in contrast to genuine 'judgments,' they make no claims of 'striking' an

43 Ibid., 168.

44 Ibid., 172.

45 Ibid., 160. 
objective state of affairs." 46 This applies to statements which appear in a fictional work.

There are several criteria allowing one to distinguish actual propositions from quasi-propositions. Some of them are: when reading aloud sentences belonging to a fictional work we give them a different intonation than we would give to the same sentences if they were to appear in a scientific work. Another difference is that the title or subtitles of works inform us of the nature of the work in question $i$. e. whether it is a novel or scientific treatise. 47 What is lacking with regard to the quasi-propositions found in a fictional work as opposed to the propositions found in a scientific one is that in the case of the former, there is no identification with the mode of the fully serious, there is no anchoring of their meaning contents in the actually existing nor is there the intention for this to happen. 48

It is this peculiar nature of quasi-propositions and quasijudgments and the objects they project which "allows us to plunge into the simulated world and live in it as a world peculiarly unreal and yet having the appearance of reality." 49

46 Ibid., 131.

47 Ibid., 179. Ingarden proposes that one could introduce a special sign that one puts before quasi-judgments to distinguish them from actual judgments not unlike what was proposed by Bertrand Russell and his assertion sign currently used in symbolic logic.

48 Ingarden, The Literary Work, 171.

49 Ibid., 172. 
Another peculiarity of quasi-propositions and quasi-judgments and the objects they project, i.e. derived purely intentional objects that are projected from the meaning units of the sentences found in fictional works, is for Ingarden: "Now, objects ... even though, according to their content, ... are usually of the nature of real objectivities[, t]heir ontic heteronomy, which allows them only to pretend real existence in their content, necessarily also brings about the fact that the time belonging to the represented quasi-real world is only an analogue of real time." 50 This is because real time is, as Ingarden points out, a "continuous medium" which has no gaps in its occurrence in the real world (regardless of any subjective experiences to the contrary), whereas in fictional worlds, "only isolated 'segments' of 'reality'... are represented, a reality which is being represented but which is never representable in its flowing continuity. The reason for this lies precisely in the fact that the represented world [that which is projected by many inter-connected meaning units] has the source of its existence and essence solely in a finite number of sentences". 51

\section{Ideal Concepts Needed for Intersubjective Identity of Sentences}

As was seen earlier Ingarden does not believe that meanings of words or sentences have either a real or an ideal existence. He does however hold the position that there are such things as ideal meaning units or ideal concepts. An example of an ideal concept would be something

50 Ibid., 236.

51 Ibid., 237. 
that had timelessness as one of its attributes, and would therefore be of an absolute unchangeable nature. The idea of a perfect triangle fits this requirement nicely. Because of material limitations a real triangle could never be perfect because it is impossible for the intersecting lines of any triangle to match perfectly. (Of course practically speaking one could come up with a nearly perfect triangle.) This shows that it is possible for us to have the idea of a perfect entity (e.g. triangle) and yet we could never produce this perfect entity in actual physical reality.

The relationship between Ingarden's ideal concepts and word meanings is similar to the relationship between the perfect triangle and the many different particular triangles of various sizes and different materials which are based on this perfect triangle. But first we need to make a distinction between word meanings and ideal concepts. Ingarden tells us that "it is part of the idea of meaning that it be bound to some word sound (or to some sign of a visual, acoustic, or tactile nature) and hence be its meaning. ...Without the "word sound'... [meanings] could not exist at all."52 Ingarden holds that meanings are very different from ideal concepts. However, one makes use of ideal concepts in the creation of sentences, for "each ideal concept has a number of word meanings for the same object." ${ }^{n 3}$ In just this way, one can have many different types of individual triangles, and yet they are all triangles. Ingarden tells us that:

A word meaning ... is nothing other than an actualization of the meaning contained in the corresponding ideal, ontically autonomously existing concepts. Moreover, it is at any one

52 Ibid., 59.

53 Ibid., 87. 
moment an actualization of only part of this meaning. This actualization and formation of a unified whole out of component parts is realized through sentence-forming operations whereby they immediately produce word meanings in the form in which they must appear as component parts of a determinate sentence or a determinate sentence complex. Through this actualization something new is undoubtedly produced: the meaning content of the sentences or the meaning content of a sentence complex. Ideal concepts are not component parts of these formations. They are as transcendent with respect to them as are subjective operations, and they are also transcendent with respect to the latter and remain beyond the reach of their influence. But they do constitute the ontic basis of sentences and the regulative principle of their formation. In consideration of their ideal meaning content, the conscious subject selects appropriate moments in them, brings about their ontically heteronomous actualization, and unites them into a new whole. ${ }^{54}$

I will attempt to explain what Ingarden means in the above quotation. The analogy of a perfect triangle and its relationship to many different individual triangles I think does not fully reveal the nature of meanings and the ideal concepts they rely on. So let us use an example more in line with what would be found in a literary or fictional work. Let us use the ideal concept of "love" and show how one only uses certain aspects or shades of its meaning in the writing of a play or a novel. For example, one uses words and sentences to create individual characters who express imperfect notions or only certain aspects of what it means to be a human being and how love of some type is expressed in their lives. The ideal concept of "love" itself has many meanings imbedded

54 Ibid., 361. 
within it and an author only pulls certain aspects out from this concept to use for the word to describe the specific type of love that he wants to portray for any one particular character. According to Ingarden each meaning that one produces by the subjective process of binding word sounds into new complete wholes is a new creation accomplished by the author. These sentences are new creations especially when they are created for the purpose of building up a fictional world.

Ideal concepts are needed for the identity and unity of a literary work for:

It is only with reference to the meaning content of ideal concepts that readers of a literary work can reactualize in an identical manner the meaning content of sentences given to them by the author. If there were no ideal concepts and, furthermore, no ideal qualities (essences) and ideas, not only would sentences or real and intentional objectivities be impossible; it would also be equally impossible to achieve between two conscious subjects genuine linguistic communication, in which both sides would apprehend an identical meaning content of the sentences exchanged. There frequently are misunderstandings between two speakers, and, practically speaking, they frequently cannot apprehend identically the same sentences. But with the existence of ideal concepts there is at least in principle the possibility that, by recourse to the corresponding objectivities and by apprehending at least part of the meaning content of the corresponding ideal concepts, each of the speakers succeeds in forming or constituting a sentence with a meaning content identical to the other's and hence understanding the sentence spoken by the other. 55

Ideal concepts are needed, according to Ingarden, because without them people would not be able to communicate. When two

55 Ibid., 364. 
people do communicate each one knows what the other is saying because each person has an idea of the ideal concepts that were used to create the individual and particular instances of the meanings that participated with some aspect of their corresponding ideal concept. These instances of participation of words and sentences with their corresponding ideal concepts are specifically the meanings of the words and sentences used in that communication. Ingarden tells us: "... the work (or the sentence) exists as soon as it is created. But it exists as an ontically autonomous heteronomous formation that has the source of its existence in the intentional acts of the creating conscious subject and, simultaneously, the basis of its existence in two entirely heterogeneous objectivities: on the one hand, in ideal concepts and ideal qualities (essences), and, on the other hand... in real word signs."56

Ingarden does believe that there are such things as ideal concepts and essences but at the same time if there were no conscious individuals who participated in "sentence-forming operations" 57 then we would never have any sentences. This has consequences for our theories concerning the existence and type of being fictional objects have. For as we have seen fictional objects transcend and are different from the meanings used to project them but they are at the same time dependent upon meanings for their existence. They are in this way different from ideal concepts or any type of ideal object in that fictional objects are subject to

56 Ibid., 361.

57 Ibid., 102. 
transformations by the subjective sentence-forming operations of an author. An author can for instance cause profound transformations to occur to any particular character or even to the world or universe that had been created.

\section{CONCLUSION}

We have seen that fictional objects are those entities which are created by specifically original acts of consciousness. They come into being and exist only by our actions but they have the ability to be shared and become part of our lives. In this paper we have seen that fictional objects are not "nothing," that they do have a type of existence. They are not purely mind-dependent entities either, but rather entities that transcend the mind of any one individual person and yet could not exist if it were not for the peculiar nature of meanings and their use in our lives. 


\section{BIBLIOGRAPHY}

Crittenden, Charles. 1991. UNREALITY The Metaphysics of Fictional Objects. Ithaca, NY: Cornell University Press.

Falk, Eugene H. 1981. The Poetics of Roman Ingarden. Chapel Hill, NC: The University of North Carolina Press.

Ingarden, Roman. 1973. The Literary Work of Art. An Investigation on the Borderlines of Ontology, Logic and Theory of Literature. George G.

Grabowicz trans. Evanston, Illinois: Northwestern University Press.

1976. The Cognition of the Literary Work of Art. Ruth Ann

Crowley and Kenneth R. Olson. trans. Evanston Illinois:

Northwestern University Press.

Linsky, Leonard 1967. Referring. New York: Routledge and Kegan Paul.

Magliola, Robert R. 1977. Phenomenology and Literature. Indiana: Purdue University Press.

Rieser, Max. "Roman Ingarden and His Time." Journal of Aesthetics and Art Criticism. 1971. Vol. 29. p. 443-452.

Smith, Barry. "Ingarden Versus Meinong on the Logic of Fiction." 1980 1981. Philosophy and Phenomenological Research. Vol. 41. p. 93105. 